\title{
THE EXCRETION OF GLUCURONIC ACID AND OF ACID MUCOPOLYSACCHARIDES IN NORMAL HUMAN URINE ${ }^{1}$
}

\author{
BY GRACE P. KERBY \\ (From the Department of Medicine, Duke University School of Medicine, Durham, N. C.)
}

(Submitted for publication March 1, 1954; accepted April 21, 1954)

The urinary excretion of acid mucopolysaccharides has been a subject of controversy. Acid mucopolysaccharides are polymers of disaccharides composed of equimolar portions of $\mathrm{N}$-acetyl or $\mathrm{N}$-sulfate hexosamine and hexuronic acid, occurring either free or as esters of sulfuric acid and in loose combination with protein substances. They include such substances as chondroitin sulfate, heparin and hyaluronate. The evidence for and against the urinary excretion of chondroitin sulfate was reviewed briefly by Oliver (1) whose own experiments led him to the conclusion that an "X-body," similar in some of its characteristics to chondroitin sulfate, was one of several urine constituents which influenced the precipitation of urinary proteins. Astrup (2) was particularly interested in the excretion of heparin and devised a method for extracting from urine metachromatic substances which would inhibit clotting. His method was later used by Jacques, Napke, and Levy (3) to study in greater detail the recovery of injected heparin from the urine of humans and various animals. Metachromatic material obtained from normal urine was noted by these investigators to be so small in amount that its presence did not interfere with their study of additional metachromatic substances excreted after the injection of heparin.

In studying acid mucopolysaccharides, one must to some extent be concerned with their hydrolytic products. One of the important components of most ${ }^{2}$ acid mucopolysaccharides is hexuronic

\footnotetext{
1 This investigation was supported in part by grants from the National Institute of Arthritis and Metabolic Diseases of the National Institutes of Health, Public Health Service; Baxter Laboratories, Inc.; Duke University Research Council.

2 Meyer, Linker, Davidson, and Weissmann (4) described a mucopolysaccharide (keratosulfate) of bovine cornea which is composed of $\mathrm{N}$-acetylglucosamine, galactose, and sulfate.
}

acid. For reasons of convenience and interest, this component has been emphasized considerably more in the present studies than has the equally important hexosamine component. The metabolism of glucuronic acid is not well understood. Mosbach and King (5) and Eisenberg and Gurin (6) have contributed useful data based on tracer studies, and Levvy (7) has reviewed the available material on the role of $\beta$-glucuronidase and related enzymes. Fishman, Smith, Thompson, Bonner, Kasdon, and Homburger (8) studied the effect of the ingestion of glucuronolactone on the blood levels of glucuronic acid in humans. They recorded the urinary excretion of glucuronic acid, also, in a few patients who were given glucuronolactone by mouth and concluded that little of the substance was excreted in the urine. Ormsby (9) also noted that urinary excretion of glucuronic acid accounted for only 15 to 20 per cent of an ingested dose of glucuronolactone in man. The total excretion of glucuronic acid in the urine represents the very small portion which occurs as a constituent of the acid mucopolysaccharides but also the much larger portion which is excreted as a constituent of a variety of other substances unrelated to acid mucopolysaccharides.

The present study is concerned chiefly with acid mucopolysaccharides isolated from the urine of normal humans by the method of Astrup (2). Quantitative studies were based on the measurement of glucuronic acid following acid hydrolysis of the Astrup fraction. Qualitative studies were chromatographic in nature and demonstrated the presence in the fraction of a substance showing the same $R_{\mathbf{f}}$ value as chondroitin sulfate. Ingestion of glucuronolactone was shown to increase significantly not only the direct excretion of glucuronic acid in urine but also the excretion of acid mucopolysaccharides. 


\section{METHODS}

Subjects. Subjects were personnel associated with the laboratory. Collections of 24-hour urines were not always on consecutive days during the period of baseline observations. Baseline collections always included, however, at least two days immediately prior to the ingestion of glucuronolactone and two to three days immediately following cessation of the drug. Glucuronolactone was administered in a single 5-gram oral dose on each of three to six consecutive days.

The patient on whom the data of Table I were obtained was an otherwise healthy young white male with a chronic duodenal ulcer.

TABLE I

Effect of prostatic secretions on urinary content of glucuronic acid and acid mucopolysaccharides

\begin{tabular}{ccc}
\hline $\begin{array}{c}\text { Normal o } \\
\text { white, aet 31 }\end{array}$ & $\begin{array}{c}\text { Mg. of glucu- } \\
\text { ronic acid- } \\
\text { per 100 ml. } \\
\text { of urine }\end{array}$ & $\begin{array}{c}\text { Mg. of glucu- } \\
\text { ronic acid in } \\
\text { Astrup fraction } \\
\text { per 100 ml. } \\
\text { of urine }\end{array}$ \\
\hline $\begin{array}{c}\text { Before prostatic } \\
\text { massage }\end{array}$ & 59.0 & 0.907 \\
$\begin{array}{c}\text { After prostatic } \\
\text { massage }\end{array}$ & 57.5 & 0.849 \\
\hline
\end{tabular}

TABLE II

Glucuronic acid and acid mucopolysaccharide content of urine obtained from renal pelvis of patient, post-nephrostomy, with previous unilateral nephrectomy

\begin{tabular}{ccc}
\hline \hline $\begin{array}{c}\text { Post- } \\
\text { operative } \\
\text { day }\end{array}$ & $\begin{array}{c}\text { Mg. glucuronic } \\
\text { acid per } \\
\text { 24-hour urine }\end{array}$ & $\begin{array}{c}\text { Mg. glucuronic } \\
\text { acid in Astrup } \\
\text { fraction of } \\
\text { 24-hour urine }\end{array}$ \\
\hline 1 & 1,411 & 7.20 \\
2 & 787 & 11.98 \\
3 & 255 & 7.23 \\
4 & 178 & 6.59 \\
5 & 106 & 4.26 \\
\hline
\end{tabular}

The patient on whom the data of Table II were obtained was a 67-year old colored woman with a previous unilateral nephrectomy, on whom a nephrostomy was done. The 24-hour urine collections from the nephrostomy tube constituted, therefore, the patient's total urinary output. Collections were terminated when evidence of urinary tract infection appeared post-operatively.

Isolation of acid mucopolysaccharides from urine. The method of Astrup (2) was followed closely.3

In patients eating diets which impose rigid sodium restriction, it has been found necessary to add additional salts to the urine prior to using benzidine $\mathrm{HCl}$ in order to obtain maximal precipitation of acid mucopolysaccharides. For the sake of uniformity, this step has been

\footnotetext{
${ }^{3}$ By this method, not less than 80 per cent of added heparin ( $300 \mathrm{mcg}$. per $50 \mathrm{ml}$. of urine) could be recovered consistently.
}

used subsequently routinely with urine from both patients and a new series of controls. The yield of Astrup fraction from controls on ordinary diets is somewhat greater by this means than by the method used in the present study.

Quantitative studies of the acid mucopolysaccharide fraction. The glucuronic acid content of the Astrup fraction was determined by acid hydrolysis and subsequent production of the carbazole color reaction of Dische (10). Quadruplicate tubes for hydrolysis were set up on each Astrup fraction, one tube later serving as a blank, receiving $0.2 \mathrm{ml}$. of alcohol instead of $0.2 \mathrm{ml}$. of an alcoholic solution of carbazole. DuPont Sulfuric Acid C. P. Reagent was used.4 A standard curve based on readings obtained with glucuronolactone in duplicate 20,30 , and 40 gamma amounts was included in every set of determinations throughout the studies. Samples were discarded if the highest and lowest of the readings (optical densities at $530 \lambda$ on a Coleman Junior Spectrophotometer) on the triplicate hydrolysates failed to check within 15 per cent of each other. The entire run was discarded if the duplicate readings on the standard curve failed to check within 15 per cent or if the standard curve did not pass within 0.035 of the zero point.

Qualitative studies of the acid mucopolysaccharide fraction. Chromatographic studies were carried out, using $15 \times 22-1 / 2$ inch sheets of Whatman No. 1 filter paper, ascending, six sheets per run in a chromatocab. The solvents used were propanol or ethanol in $\mathrm{pH} 6.5$ $M / 15$ phosphate buffer for 72 and 48 hours, respectively, at $76^{\circ} \mathrm{F}$. The concentrations of alcohol used are indicated in the accompanying Figures 5 and 6 . The known substances with which the urine samples were compared were chondroitin sulfate (General Biochemicals, Inc.) and Heparin Sodium (Liquaemin; Organon, Inc.) each applied one time to the filter paper, in concentration of 5 and $6 \mathrm{mg}$. per ml. of distilled water, respectively (11). 5

The urine samples were prepared for chromatography as follows: The Astrup fraction containing acid mucopolysaccharides from $50 \mathrm{ml}$. of urine was taken up in 5 to $10 \mathrm{ml}$. of distilled water and dialyzed first against 20 volumes of distilled water with constant shaking for 15 to 16 hours at $5^{\circ} \mathrm{C}$., then against $70 \mathrm{ml}$. of 20 per cent aqueous polyvinylpyrrolidone with constant rotation in a cylinder for 24 hours at $7^{\circ} \mathrm{C}$. The contents of the dialysate casing were then taken up in $0.4 \mathrm{ml}$. of distilled water, yielding a small amount of very slightly viscid fluid material varying in appearance from clear colorless to clear or turbid yellow or brown. On filter paper the material stained metachromatically with toluidine blue. For chromatographic runs, it was usually applied three times to the starting point, with drying between appli-

- A green color resulted from the use of several other brands of commercial sulfuric acid tried.

S Subsequent to the publication of (11), the interesting study of Molho and Molho-Lacroix (12) has come to the author's attention, in which chromatograms were achieved on filter paper by the use of a propanol-water solvent for aqueous heparin and an acetone-water solvent for heparin added to plasma. 
cations. It was necessary that the material be present in sufficient concentration to stain metachromatically, but overloading caused streaking. The attempt was to achieve maximal concentration without encountering overloading effects.

The chromatograms were developed by a technique developed in this laboratory and similar to that used by Rienits (13). The technique is reported in detail elsewhere (14). The major technical differences from Rienits' method consist of the fixation of the watersoluble materials on the paper prior to staining with aqueous toluidine blue and then much more complete rinsing in water which has been acidified with glacial acetic acid. The resultant metachromatic spots are quite stable against a blue background.

Quantitative studies of the total urinary output of glucuronic acid. The total excretion of glucuronic acid in urine was determined, also, using appropriate dilutions of urine in the colorimetric method of Dische (10). These were set up always in triplicate tubes for hydrolysis, using one, later, for a color blank, as before.

\section{RESULTS}

Results are graphically summarized in Figures 1 to 4 . The difference in excretion of acid muco-

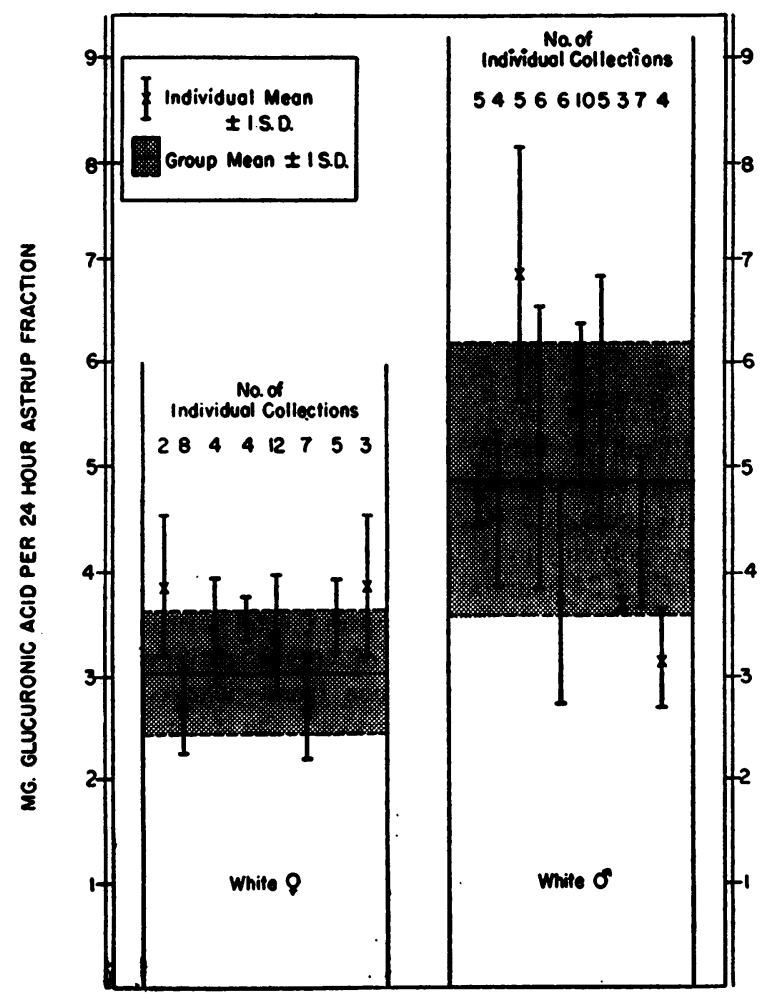

FIG i. 24 HOUR URINARY EXCRETION OF ACID MUCOPOLYSACCHARIDES (DXPRESSED AS MG OF GLUCURONIC ACID) BY NORMAL HUMAN ADULTS

FIG. 1

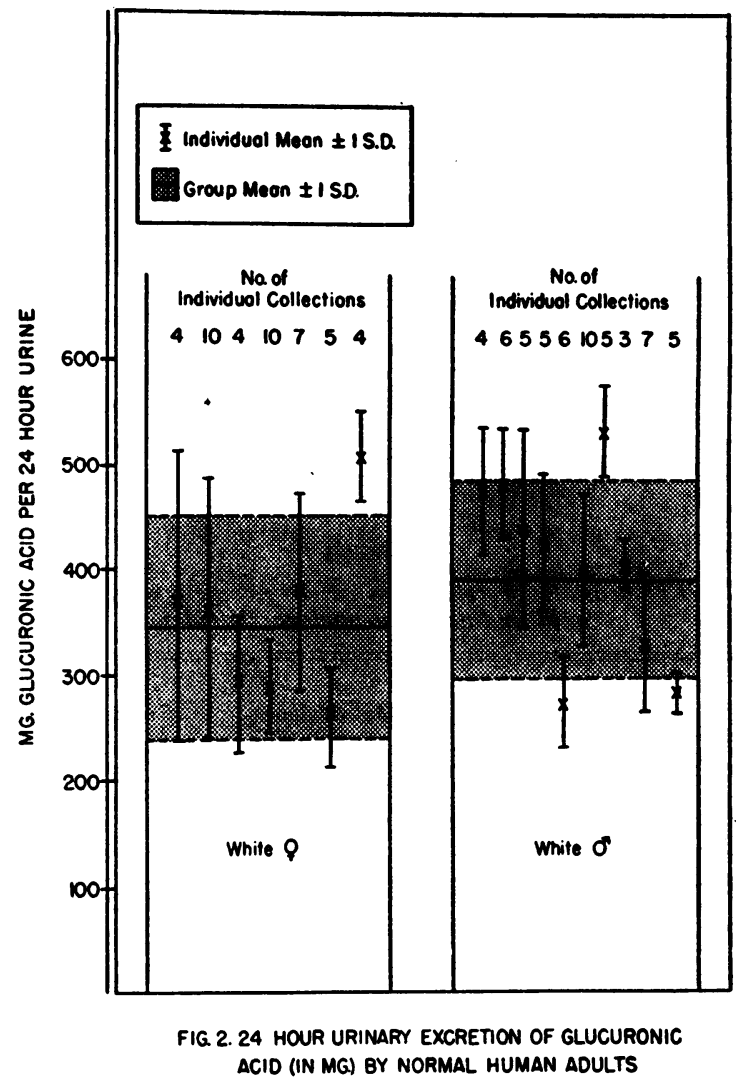

FIG. 2

polysaccharides (expressed as mg. of glucuronic acid after hydrolysis) between normal white males and females (Figure 1) is of high statistical significance $(p=<0.01)$. This is in contrast to the excretion of total glucuronic acid which is essentially the same in white males and females. (Figure 2).

Because of the greater individual standard deviation in excretion of acid mucopolysaccharides by males as compared to females, the possibility of a prostatic derivation of part of the material was entertained. Table I illustrates data on one patient which fail to support this likelihood. The observations were repeated in another patient with similar results.

Data on molecular size of acid mucopolysaccharides are conflicting but some estimates range as high as 200,000 to 400,000 (15). Glomerular filtration in this form, then would be improbable. However, Table II illustrates the presence of these 


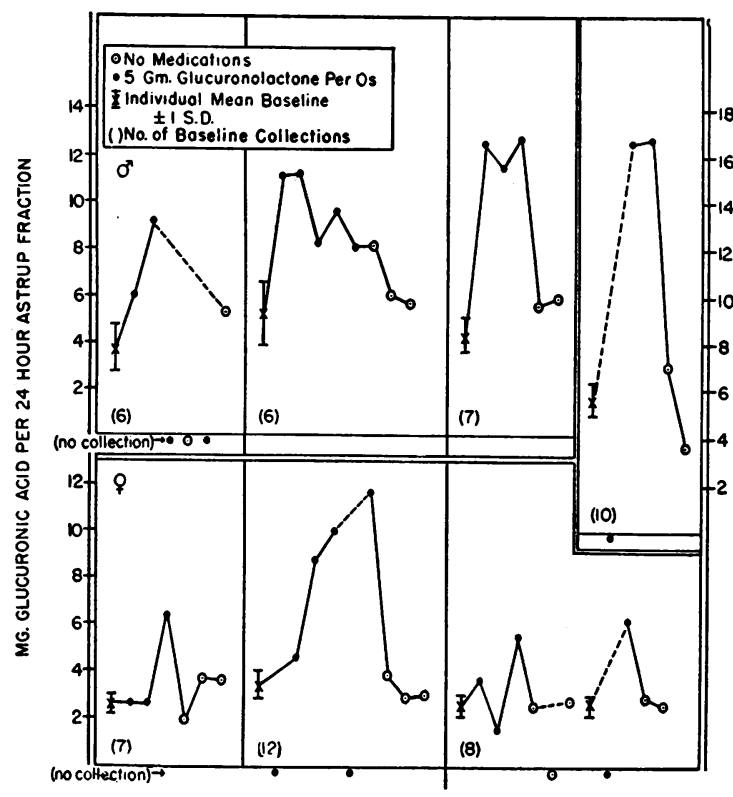

FIG. 3. EFFECT OF INGESTION OF GLUCURONIC ACID ON THE 24 HOUR URINARY EXRETION OF ACIO MUCOPOLYSACCHARIDES

FIg. 3

The abscissae represent successive days on which 24hour collections of urine were made during and following the experimental period of ingestion of glucuronolactone.

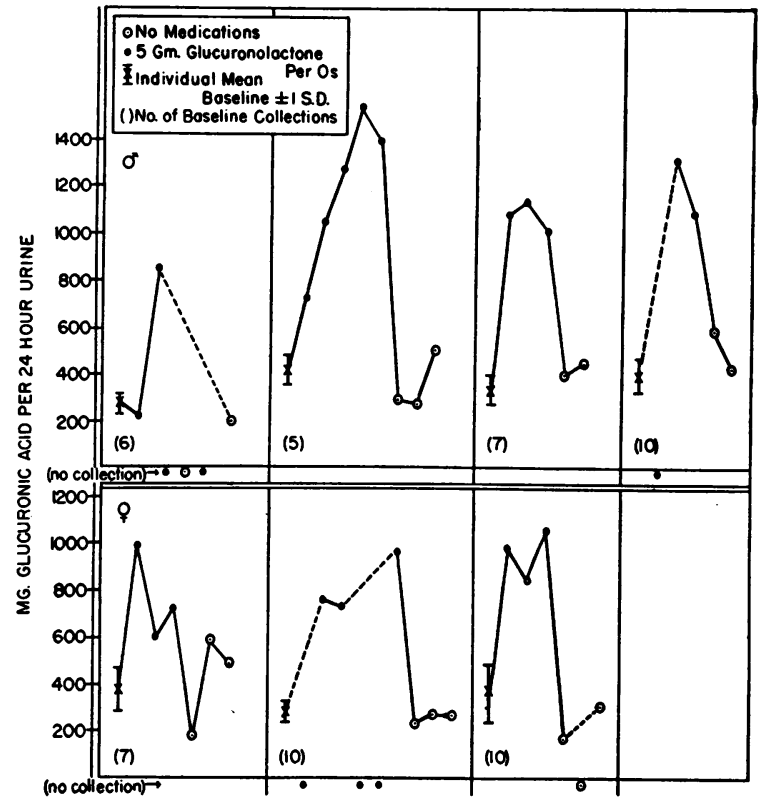

FIG. 4. EFFECT OF INGESTION OF GUCURONIC ACID ON THE URINARY EXCRETION OF GLUCURONIC ACID

FIg. 4

The abscissae are as for Figure 3.

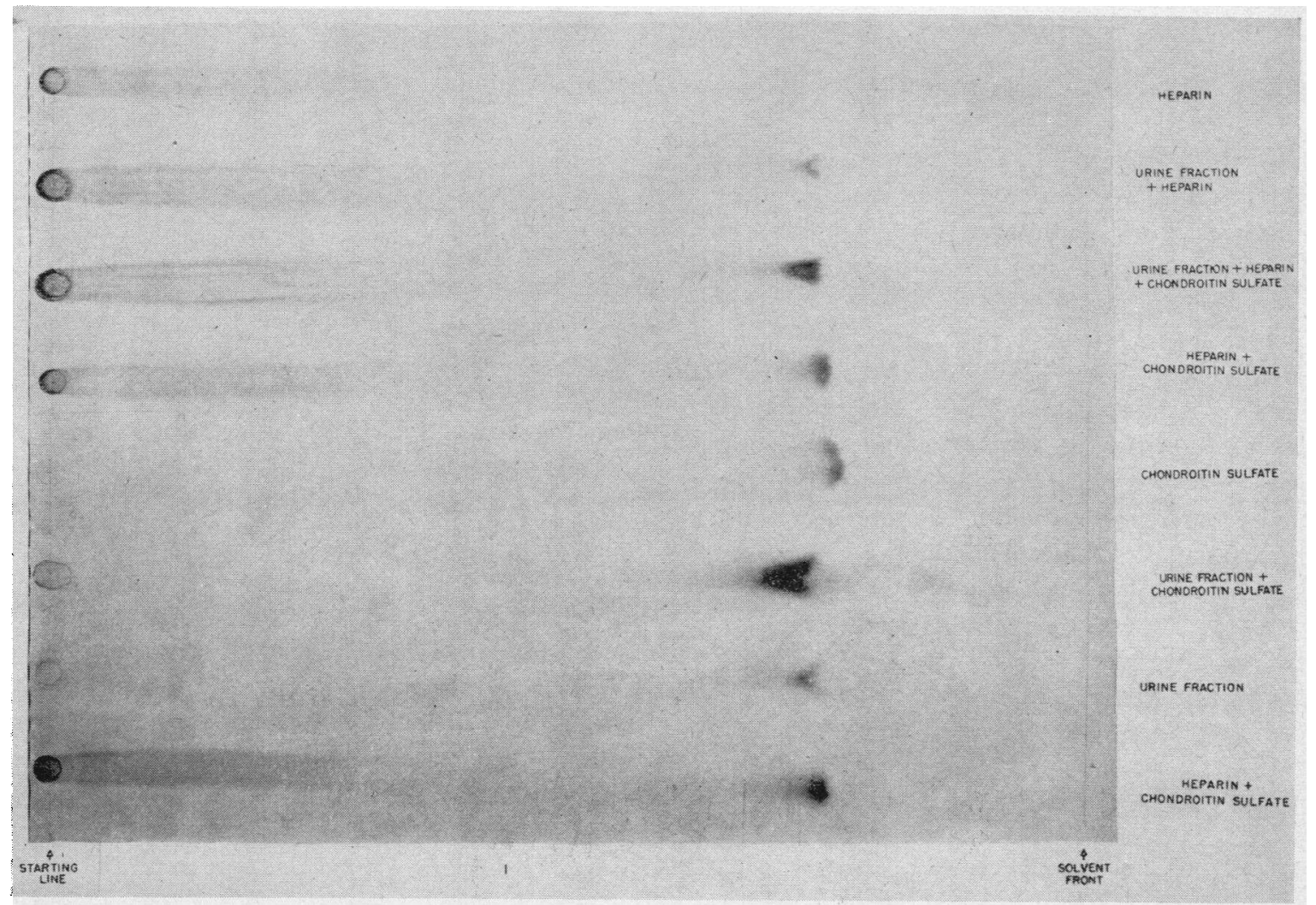

Fig. 5. Urine Fraction from Normal White Female

Solvent 52 per cent ethanol in pH $6.5 \mathrm{M} / 15$ phosphate buffer. 


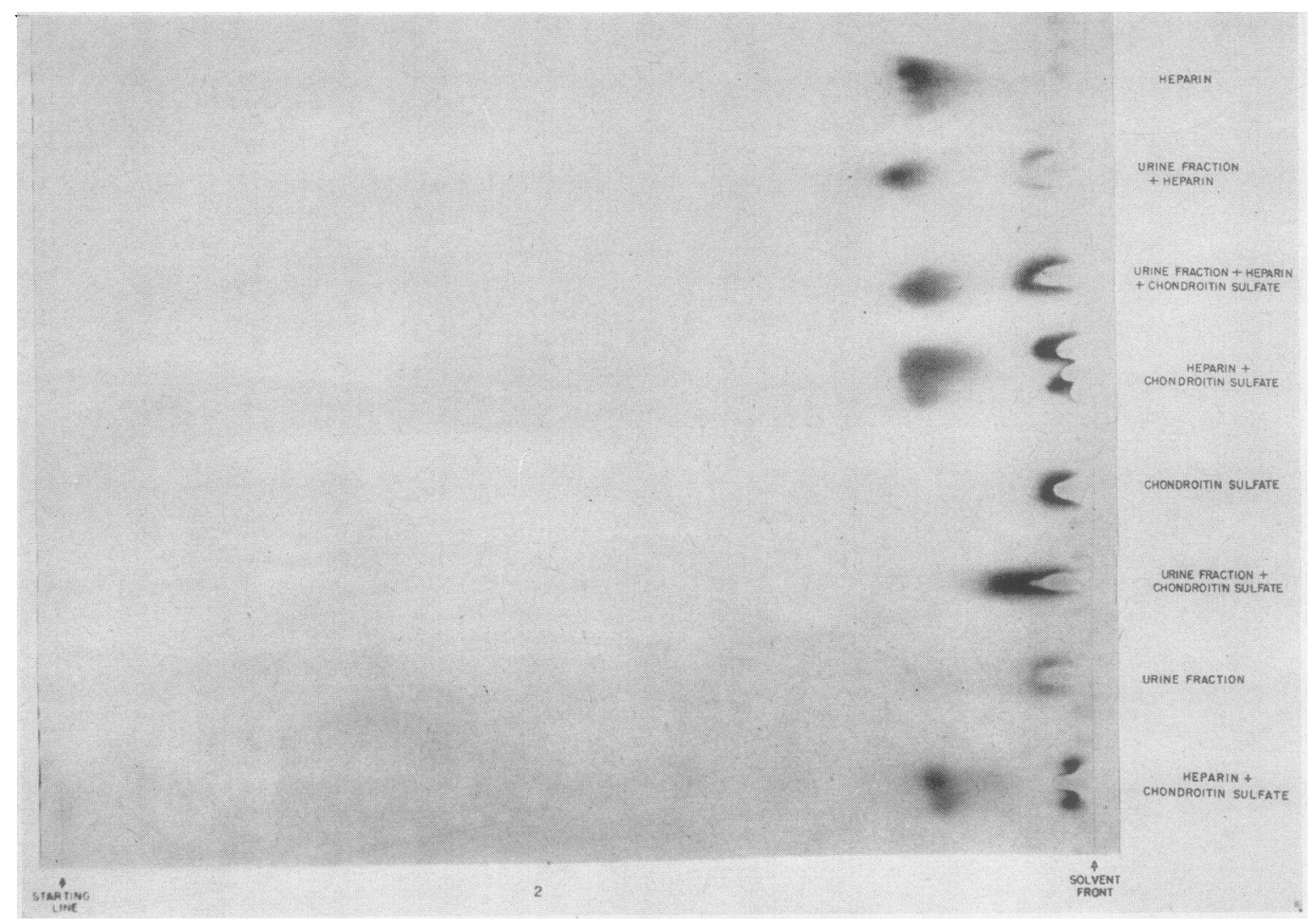

Fig. 6. Urine Fraction from Normal White Female

Solvent 37 per cent propanol in $\mathrm{pH} 6.5 \mathrm{M} / 15$ phosphate buffer.

materials in the renal pelvis in amounts which are relatively high. ${ }^{6}$

Figures 5 and 6 illustrate chromatograms of a urine sample from one normal female, run both separately and mixed with the known substances, chondroitin sulfate and heparin. These are essentially representative of the other normal individuals so tested, although there were instances in which it appeared impossible to add sufficient material for a spot which could be photographed without encountering streaking due to overloading. A urine sample of the nephrostomy patient previously described showed a similar chromatographic pattern. The chromatograms show the major urinary component to have the same $R_{f}$ value as chondroitin sulfate and to move as a single spot when mixed with chrondroitin sulfate.

6 The possibility which is suggested by the data that there is a rise post-operatively in the excretion of these substances is currently under investigation, both in surgical patients and in stressed non-surgical individuals.

\section{DISCUSSION}

The total excretion of glucuronic acid in the urine of normal individuals is of the same order of magnitude as noted by other investigators ( 9 , 16) (Figure 2). A significant rise in excretion occurs on the ingestion of glucuronolactone (Figure 4), although most of the ingested material does disappear elsewhere. Of greater interest in the present study is the significant rise in the excretion of acid mucopolysaccharides in the urine of normal individuals following the ingestion of glucuronolactone. This is not due to a nonspecific precipitation of glucuronic acid with the Astrup fraction, because very large amounts of glucuronolactone, menthol glucuronide and borneol glucuronide can be added to urine prior to isolation of the Astrup fraction without altering in any way the subsequent yield of glucuronic acid obtained from the acid mucopolysaccharide fraction. It is possible, therefore, that the ingested glucuronic 
acid enters a metabolic pool concerned with acid mucopolysaccharides, the excess being in part excreted in this form. The rise in excretion of acid mucopolysaccharides did not always occur on the first day of ingestion of glucuronic acid. However, no consistent delay could be demonstrated (Figure 3) which might be considered the time necessary for production of the material. Tracer studies would be helpful in this regard. Urine collections over 6-hour periods continuously for six days, including a 2-day period of ingestion of glucuronolactone, yielded data which failed to show any consistent peak of excretion of acid mucopolysaccharides, either during baseline collections or following ingestion of glucuronolactone.

The daily excretion of acid mucopolysaccharides is relatively constant in each individual but varies to a greater degree between individuals. Why both individual and group variations should be greater in males than in females is unexplained at the moment. The wide variations which occur under certain experimental and clinical situations and in certain disease processes form the subject of separate investigations now in progress and beyond the scope of the present report.

The way in which acid mucopolysaccharides get into urine is not certain. The present study demonstrates that the material was present in urine collected from the renal pelvis. This observation plus that of failure to show a rise in urinary acid mucopolysaccharides following prostatic massage make it unlikely that any appreciable amount of the material is added in the lower urinary tract. The data yield no evidence bearing on the question of secretion by the renal tubular epithelial cells. However, the studies of Piper (17) on the fate of heparin injected into rabbits led him to the conclusion that that portion of the heparin which was excreted by way of the kidneys was handled by a combination of glomerular filtration and tubular secretion. Consideration of glomerular filtration requires consideration of molecular size. By streaming birefringence, Blix and Snellman (15) estimated the molecular weight of chondroitin sulfuric acid to be of the order of 260,000. By osmometry, Mathews and Dorfman (18) estimated molecular weights of 15,000 to 43,000 for chondroitin sulfuric acid, variations occurring with variations in method of separating the material for study. Discrepancies, therefore, may result not only from the fact that these substances are probably not pure and of single molecular weight but also because the shape of the molecule may vary in different environments, with consequent effect on estimates of molecular weight by various methods. If materials of large molecular weight are considered in regard to glomerular filtration, the possibility is raised that the materials circulate in the blood in the form of a smaller structural unit which may be filtered through the glomerulus, later polymerizing in the tubules to form the substance isolated in the present study from urine obtained from the renal pelvis. The concept of smaller-sized components of ground substance is not a new one (19). However, since it is still purely speculative and since even the question of original molecular size is unsettled, the advice of Meyer (20) is followed in the avoidance of any debate as to whether such smaller units, if they occur, result from depolymerization, lack of polymerization, or formation of an entirely different unit of similar structure but smaller size than the acid mucopolysaccharides. Of greater interest, perhaps, is consideration of the smaller molecular size estimated by Mathews and Dorfman (18). Acid mucopolysaccharides of molecular weight 43000 or less might quite reasonably be expected to be filtered through the glomerulus. This would raise interesting questions as to whether the bulk of the material is then reabsorbed by the renal tubules as in the case of filtered serum albumin or whether it is excreted as filtered. Present methods fail to detect with certainty acid mucopolysaccharides as such in normal blood. However, the 24-hour excretion of these substances is small and could be accounted for by very minute amounts in plasma filtered at the rate of 180 liters per day.

The character of at least one and apparently the major component present in the acid mucopolysaccharide fraction from human urine is on more solid ground. Although the identity of the component is not fully established, it does exhibit the same $R_{f}$ value chromatographically in a single solvent system as does chondroitin sulphate, and it moves as a single spot chromatographically when mixed with chondroitin sulphate. 


\section{SUMMARY}

The mean 24-hour excretion of glucuronic acid in normal human urine was $345 \mathrm{mg}$. \pm 44 (S.D.) in white females and $391 \mathrm{mg}$. \pm 56 in white males. There is no significant difference between the two values.

The mean 24-hour excretion of acid mucopolysaccharides (expressed as glucuronic acid after hydrolysis) in normal human urine was $3.0 \mathrm{mg}$. \pm 0.6 (S.D.) in white females and $4.9 \mathrm{mg}$. \pm 1.3 in white males. The difference between the two values was significant $(p=<0.01)$. Prostatic massage did not increase the amount of the material in urine. The material was present in urine obtained from the renal pelvis of one patient and thus was not derived to any significant degree in that patient from structures lower in the urinary tract.

The urinary excretion of acid mucopolysaccharides by humans was markedly increased by the ingestion of $5 \mathrm{Gm}$. of glucuronolactone daily for several days.

Chromatographic studies of a further purified fraction of acid mucopolysaccharides from normal human urine showed the major component of the fraction to have the same $R_{f}$ value as chondroitin sulfate and to produce a single spot when mixed with chondroitin sulfate, in a single solvent system.

\section{ACKNOWLEDGMENT}

This work was done with the technical assistance of Mrs. Dorothy Bilancio.

\section{REFERENCES}

1. Oliver, J., New directions in renal morphology: a method, its results and its future. Harvey Lectures, 1944-1945, 40, 102.

2. Astrup, $P$., On the determination of heparin in blood plasma and urine. Acta pharmacol. et toxicol., 1947, 3, 165.

3. Jacques, L. B., Napke, E., and Levy, S. W., The metachromatic activity of urine following the injection of heparin. Circ. Research, 1953, 1, 321.
4. Meyer, K., Linker, A., Davidson, E. A., and Weissmann, B., The mucopolysaccharides of bovine cornea. J. Biol. Chem., 1953, 205, 611.

5. Mosbach, E. H., and King, C. G., Tracer studies of glucuronic acid biosynthesis. J. Biol. Chem., 1950, 185, 491.

6. Eisenberg, F., Jr., and Gurin, S., Biosynthesis of glucuronic acid from 1-C $\mathrm{C}^{14}$-glucose. J. Biol. Chem., 1952, 195, 317.

7. Levvy, G. A., $\beta$-glucuronidase and related enzymes. Brit. Med. Bull., 1953, 9, 126.

8. Fishman, W. H., Smith, M., Thompson, D. B., Bonner, C. D., Kasdon, S. C., and Homburger, F., Investigation of glucuronic acid metabolism in human subjects. J. Clin. Invest., 1951, 30, 685.

9. Ormsby, A. A., The metabolism of glucuronic acid in man. Texas Rep. Biol. \& Med., 1952, 10, 66.

10. Dische, Z., A new specific color reaction of hexuronic acids. J. Biol. Chem., 1947, 167, 189.

11. Kerby, G. P., Chromatographic separation of heparin and chondroitin sulfate. Proc. Soc. Exper. Biol. \& Med., 1953, 83, 263.

12. Molho, D., and Molho-Lacroix, L., Chromatographie de partage sur papier de l'héparine en solutions aqueuse et plasmitique. Compt. rend. Acad. d. sc., 1952, 235, 522.

13. Rienits, K. G., The electrophoresis of acid mucopolysaccharides on filter paper. Biochem. J., 1953, 53, 79.

14. Leitner, J. G., and Kerby, G. P., The staining of acid mucopolysaccharides after chromatography on filter paper. Stain Technol., In press.

15. Blix, G., and Snellman, O., Molecular shape and size of hyaluronic acid and chondroitinsulphuric acid. Nature, 1944, 153, 587.

16. Brox, G., Beiträge zum Glukuronsäurestoff wechsel. I. Zur Physiologie. II. Zur Pathologie. Deut. Z. f. Verdauungs-u. Stoff wechselkrank, 1953, 13, 99, 193.

17. Piper, J., The fate of heparin in rabbits after intravenous injection. Filtration and tubular secretion in the kidneys. Acta pharmacol. et toxicol., 1947, 3, 373.

18. Mathews, M. B., and Dorfman, A., The molecular weight and viscosity of chondroitinsulfuric acid. Arch. Biochem. Biophys., 1953, 42, 41.

19. Gersh, I., Ground substance and the plasticity of connective tissues. Harvey Lectures, 1949-1950, 45, 211.

20. Meyer, K., Outline of problems to be solved in the study of connective tissues. Connective Tissues. Ragan, Charles, Ed., Trans. Fourth Conf. New York, Josiah Macy, Jr. Foundation, 1953, p. 185. 